* Graduado em Formação de Psicólogos e Licenciatura Psicologia pela Universidade de Bauru (1987), mestrado em Projetos Arte e Sociedade pela Universidade Estadual Paulista Júlio de Mesquita Filho (1994) e doutorado em Psicologia pela Pontifícia Universidade Católica de Campinas (2005). Atualmente é Professor Assistente Doutor da Universidade Estadual Paulista Júlio de Mesquita Filho. E-mail: edward@fc.unesp.br

** Graduando do curso de Direito da Universidade Estadual de Londrina (UEL). E-mail: jpdrogoulart@gmail.com

\section{RESTITUIÇÃO DO PODER FAMILIAR: CONSIDERAÇÕES ACERCA DE SUA POSSIBILIDADE JURÍDICA}

\author{
Restoration OF Family Power: Considerations About \\ ITS LEGAL POSSIBILITY
}

\section{Edward Goulart Júnior* João Pedro Minguete Goulart**}

Como citar: GOULART JUNIOR, Edward Goulart; GOULART, João Pedro Minguete. Restituição do poder familiar: considerações acerca de sua possibilidade jurídica. Revista do Direito Público, Londrina, v. 14, n. 1, p. 83-102, abr. 2019. DOI: 10.5433/1980-511X2019v14n1p83. ISSN: 1980-511X.

Resumo: O presente trabalho teve por escopo tecer considerações acerca da possibilidade da restituição do poder familiar aos genitores destituídos por sentença judicial, a partir da construção de uma revisão bibliográfica narrativa, em que a abordagem apresentada é meramente descritiva e consubstanciada em estudos revisados da literatura, análise do ordenamento jurídico e decisões dos tribunais. A revisão bibliográfica realizada pautouse pela busca de textos científicos em algumas das principais bases de dados do Direito. À luz das diretrizes consagradas no artigo 100 do Estatuto da Criança e do Adolescente (ECA), devese sempre analisar as demandas inerentes aos direitos de crianças e adolescentes com base nos princípios da proteção integral, do melhor interesse, bem como o da prevalência da família. Nesse sentido, a restituição do poder familiar pode surgir como uma das medidas específicas de proteção à criança e ao adolescente, uma vez que o rol do artigo 101 do ECA não é taxativo. Entende-se que, por se tratar de relação jurídica continuativa, para que seja possível o restabelecimento do poder familiar, faz-se necessário que os pais faltosos logrem êxito ao provar, em ação autônoma, que, de fato, superaram as condições que os fizeram perder o poder familiar.

Palavras-Chave: Poder familiar. Destituição do poder familiar. Restituição do poder familiar. Princípio do melhor interesse. Princípio da prevalência da família. 


\begin{abstract}
This paper comments on the possibility of the restoration of the institution of the family power to parents who have been justly deprived of this legal right because of judicial sentencing. In order to research this topic, this study used bibliographical review, in which the chosen approach is merely descriptive and based on revised studies, court cases and other jurisprudential texts. Furthermore, literature review was also utilized to search for judicial decisions in important court databases. Simultaneously, this study primarily focused on the Brazilian Child and Adolescent Statute, called "ECA". More specifically, this study explored inherent children and adolescent's rights based on the principles of integral protection, best interest, as well as family prevalence. Moreover, family power restoration sometimes appears to be one of the specific measures utilized to protect children and adolescents, since the list presented in article 101 of the "ECA" is not exhaustive. Finally, this paper understands that in order to restore family power, it is necessary that failing parents prove, in an autonomous lawsuit, that, in fact, they have surpassed the conditions that made them lose the family power.
\end{abstract}

Keywords: Family power. Dismissal of family power. Restoration of family power. Best interests of the child principle. Family prevalence principle. 


\section{INTRODUÇÃO}

O artigo tem como objetivo principal fomentar a discussão sobre a possibilidade de restituição do poder familiar à luz do ordenamento jurídico brasileiro, a partir da construção de uma revisão bibliográfica narrativa, em que a abordagem apresentada é meramente descritiva e consubstanciada em estudos revisados da literatura, análise do ordenamento jurídico e decisões dos tribunais. A revisão bibliográfica realizada pautou-se pela busca de textos científicos em algumas das principais bases de dados do Direito, tais como: Portal de Periódicos Capes, Scielo, CONPEDI, LexML Brasil, Banco de Teses Capes e RT online. Por tratar-se de assunto complexo, envolvendo opiniões divergentes, a temática precisa ser abordada com cautela, uma vez que não há consenso quanto a possibilidade jurídica de se restituir o poder familiar perdido mediante decisão judicial.

Considerando o tema proposto, para início da discussão, é fundamental prestar esclarecimentos acerca de alguns dos princípios que norteiam o Estatuto da Criança e do Adolescente (ECA) e que regem seus dispositivos. O ECA, em seu artigo 100, prevê quais são os princípios inerentes a aplicação das medidas específicas de proteção às crianças e aos adolescentes. Dar-se-á ênfase neste trabalho aos previstos nos incisos II, IV e X. O inciso II, do art. 100, do ECA, positiva a proteção integral e prioritária, nos seguintes termos:

Art. $100[\ldots]$

II - proteção integral e prioritária: a interpretação e aplicação de toda e qualquer norma contida nesta Lei deve ser voltada à proteção integral e prioritária dos direitos de que crianças e adolescentes são titulares; [...] (BRASIL, 1990)

Tal dispositivo tem previsão constitucional (art. 227, CF) e consta também logo no artigo $1^{\mathrm{o}}$ do ECA, que dispõe sobre a proteção integral à criança e ao adolescente. Este princípio ampara e serve de sustentação a toda a sistemática do Estatuto da Criança e do Adolescente. Barros (2015) entende que, por proteção integral, deve-se compreender o conjunto amplo de mecanismos jurídicos voltados à tutela da criança e do adolescente e, por esta razão, o Estatuto deve ser interpretado e aplicado tendo-se sempre em vista os fins sociais a que se dirige.

O inciso IV, do art. 100, do ECA, disciplina sobre o interesse superior da criança e dos adolescentes:

Art. $100[\ldots]$

IV - interesse superior da criança e do adolescente: a intervenção deve atender prioritariamente aos interesses e direitos da criança e do adolescente, sem prejuízo da consideração que for devida a outros interesses legítimos no âmbito da pluralidade dos interesses presentes no caso concreto; [...] (BRASIL, 1990).

Este postulado traz a ideia de que, na análise do caso concreto, os sujeitos do processo devem sempre buscar a solução que proporcione o melhor benefício para a criança ou adolescente 
(BARROS, 2015).A consagração dos princípios da proteção integral, bem como do melhor interesse, superou a visão ultrapassada do já revogado Código de Menores, que tratava sobre a assistência, a proteção e a vigilância somente aos menores que se encontravam em situação irregular, conforme o artigo $1^{\circ}$ da Lei $n^{\circ} 6.697 / 1979$. De acordo com o artigo $2^{\circ}$ do referido diploma, considerava-se em situação irregular o menor: (1) privado de condições essenciais à sua subsistência, saúde e instrução obrigatória, (2) vítima de maus tratos ou castigos imoderados impostos pelos pais ou responsável, (3) em perigo moral, (4) privado de representação ou assistência legal, pela falta eventual dos pais ou responsável, (5) com desvio de conduta, em virtude de grave inadaptação familiar ou comunitária e (6) autor de infração penal (BRASIL, 1979). Atualmente, compreendemse todas as crianças e adolescentes como pessoas humanas em processo de desenvolvimento e como sujeitos de direitos civis, humanos e sociais (art. 15, ECA).

O inciso X, do art. 100, do ECA, que configura a prevalência da família, assim dispõe:

Art. $100[\ldots]$

X - prevalência da família: na promoção de direitos e na proteção da criança e do adolescente deve ser dada prevalência às medidas que os mantenham ou reintegrem na sua família natural ou extensa ou, se isto não for possível, que promovam a sua integração em família substituta; [...] (BRASIL, 1990).

Dessa forma, verifica-se que, na aplicação das medidas de proteção de crianças ou adolescentes, deve-se sempre privilegiar a sua manutenção no núcleo familiar, respeitada a preferência da família natural. Conforme elucida expressamente o ECA, em seu artigo 25, caput, entende-se por família natural a comunidade formada pelos pais ou qualquer deles e seus descendentes. Já a família extensa compreende aquela que se estende para além da unidade pais e filhos ou da unidade do casal, formada por parentes próximos com os quais a criança ou adolescente convive e mantém vínculos de afinidade e afetividade (art. 25, parágrafo único, ECA). Em respeito ao princípio da prevalência da família, o artigo 19, do ECA, elucida que é direito da criança e do adolescente ser criado e educado no seio de sua família e, apenas em caráter excepcional, em família substituta, assegurada a convivência familiar e comunitária, em ambiente que garanta seu desenvolvimento integral (BRASIL, 1990).

Nesse viés, a jurisprudência do Superior Tribunal de Justiça (STJ) se firma no sentido de que, nas disputas de custódia de crianças e adolescentes, devem ser evitadas sucessivas e abruptas alterações de guarda e residência, ressalvados os casos de evidente risco ${ }^{1}$. Assim sendo, apenas na impossibilidade de a família natural zelar adequadamente pela criança e/ou adolescente, é que a família extensa deve exercer seus cuidados e, com vistas ao princípio do melhor interesse, em situações excepcionais, é possível o deferimento da guarda de criança ou adolescente aos avós

1 Precedentes: HC 298009/SP, Rel. Ministra NANCY ANDRIGHI, TERCEIRA TURMA, julgado em 19/08/2014, DJe 04/09/2014; AgRg na MC 21782/RJ, Rel. Ministro MARCO BUZZI, QUARTA TURMA, julgado em 17/12/2013, DJe 03/02/2014; MC 20264/RJ, Rel. Ministro RICARDO VILLAS BÔAS CUEVA, TERCEIRA TURMA, julgado em 28/05/2013, DJe 03/06/2013; AgRg na MC 10531/SP, Rel. Ministro CARLOS ALBERTO MENEZES DIREITO, TERCEIRA TURMA, julgado em 11/10/2005, DJ 19/12/2005; AREsp 488308/MG (decisão monocrática), Rel. Ministro JOÃO OTÁVIO DE NORONHA, julgado em 11/04/2014, DJ 30/04/2014; MC 022129/RJ (decisão monocrática), Rel. Ministro LUIS FELIPE SALOMÃO, julgado em 16/12/2013, DJ 03/02/2014. (BRASIL, 2014). 
para atender situações peculiares, conforme entendimentos reiterados do $\mathrm{STJ}^{2}$.

\section{DO PODER FAMILIAR E SUAS HIPÓTESES DE DESTITUIÇÃO}

Na direção do objetivo deste estudo, faz-se necessário também apresentar a conceituação e implicações de poder familiar, bem como suas hipóteses de destituição, tendo por norte a Constituição Federal, o Código Civil, o Estatuto da Criança e do Adolescente (ECA) e a jurisprudência pátria.

A Constituição Federal, em seu artigo 227, traz que é dever da família, da sociedade e do Estado assegurar à criança, ao adolescente e ao jovem, os direitos a que fazem jus, na condição de sujeitos de direito:

Art. 227. É dever da família, da sociedade e do Estado, assegurar à criança, ao adolescente e ao jovem, com absoluta prioridade, o direito à vida, à saúde, à alimentação, à educação, ao lazer, à profissionalização, à cultura, à dignidade, ao respeito, à liberdade e à convivência familiar e comunitária, além de colocá-los a salvo de toda forma de negligência, discriminação, exploração, crueldade e opressão. (BRASIL, 1988).

$\mathrm{O}$ artigo $4^{\circ}$, do ECA, em seu caput, traz exatamente a mesma disposição do art. 227 da Carga Magna, no entanto, acrescenta em seu parágrafo único considerações acerca da absoluta prioridade:

Art. $4^{\circ} .[\ldots]$

Parágrafo único. A garantia de prioridade compreende: primazia de receber proteção e socorro em quaisquer circunstâncias; precedência de atendimento nos serviços públicos ou de relevância pública; preferência na formulação e na execução das políticas sociais públicas; destinação privilegiada de recursos públicos nas áreas relacionadas com a proteção à infância e juventude. (BRASIL, 1990).

Barros (2015, p. 49 apud LÔBO, 2005, p. 147-149) afirma que o poder familiar:

"[...] é o conjunto de direitos e deveres tendo por finalidade o interesse da criança (inclui o adolescente), para proteção de sua segurança, saúde, moralidade, para assegurar sua educação e permitir seu desenvolvimento, em respeito a sua pessoa".

Nesse sentido, o artigo 1.634 do Código Civil apresenta que compete a ambos os pais, qualquer que seja a sua situação conjugal, o pleno exercício do poder familiar, compreendendo, quanto aos filhos, os seguintes aspectos: (1) dirigir-lhes a criação e a educação; (2) exercer a

2 Precedentes: REsp 1186086/RO, Rel. Ministro MASSAMI UYEDA, TERCEIRA TURMA, julgado em 03/02/2011, DJe 14/02/2011; AgRg no REsp 532984/MG, Rel. Ministro VASCO DELLA GIUSTINA (DESEMBARGADOR CONVOCADO DO TJ/RS), TERCEIRA TURMA, julgado em 18/05/2010, DJe 07/06/2010; REsp 945283/RN, Rel. Ministro LUIS FELIPE SALOMÃO, QUARTA TURMA, julgado em 15/09/2009, DJe 28/09/2009; REsp 993458/ MA, Rel. Ministra NANCY ANDRIGHI, TERCEIRA TURMA, julgado em 07/10/2008, DJe 23/10/2008; REsp 1368066/DF (decisão monocrática), Rel. Ministro RICARDO VILLAS BÔAS CUEVA, julgado em 20/09/2013, DJe 02/10/2013. (BRASIL, 2013). 
guarda unilateral ou compartilhada; (3) conceder-lhes ou negar-lhes consentimento para casaram; (4) conceder-lhes consentimento para viajarem ao exterior; (5) conceder-lhes ou negar-lhes consentimento para mudarem sua residência permanente para outro Município; (6) nomear-lhes tutor por testamento ou documento autêntico, se o outro dos pais não lhe sobreviver, ou o sobrevivo não puder exercer o poder familiar; (7) representá-los judicial e extrajudicialmente até os 16 (dezesseis) anos, nos atos da vida civil, e assisti-los, após essa idade, nos atos em que forem partes, suprindo-lhes o consentimento; (8) reclamá-los de quem ilegalmente os detenha; e (9) exigir que lhes prestem obediência, respeito e os serviços próprios de sua idade e condição (BRASIL, 2002).

A Lei $\mathrm{n}^{\circ} 8.069 / 90$ (ECA), em seu artigo 21, complementa que o poder familiar será exercido, em igualdade de condições, pelo pai e pela mãe, na forma do que dispuser a legislação civil, assegurando a qualquer deles o direito de, em caso de discordância, recorrer à autoridade judiciária para a solução da divergência (BRASIL, 1990).

Pasini e Trentin (2015) argumentam que os pais possuem diversos deveres inerentes ao exercício do poder paternal e que, em algumas situações, principalmente no que tange ao descumprimento de alguma dessas prerrogativas, o Estado precisa intervir nas relações familiares, podendo suspender e até destituir o poder familiar dos genitores faltosos. Quando a família natural incorre em faltas em relação aos seus filhos, o Estatuto da Criança e do Adolescente prevê algumas formas de sanção aos genitores, veja-se:

Art. 129. São medidas aplicáveis aos pais ou responsável:

I - encaminhamento a serviços e programas oficiais ou comunitários de proteção, apoio e promoção da família;

II - inclusão em programa oficial ou comunitário de auxílio, orientação e tratamento a alcoólatras e toxicômanos;

III - encaminhamento a tratamento psicológico ou psiquiátrico;

IV - encaminhamento a cursos ou programas de orientação;

$\mathrm{V}$ - obrigação de matricular o filho ou pupilo e acompanhar sua frequência e aproveitamento escolar;

VI - obrigação de encaminhar a criança ou adolescente a tratamento especializado;

VII - advertência;

VIII - perda da guarda;

IX - destituição da tutela;

X - suspensão ou destituição do poder familiar. (BRASIL, 1990).

Além destas medidas, o artigo 249 do mesmo diploma legal, prevê, em caso de descumprimento doloso ou culposo dos deveres inerentes ao poder paternal, o pagamento de multa de três a vinte salários mínimos, podendo ser aplicada em dobro em caso de reincidência. Nesse sentido, conforme se verifica do teor do artigo 129, do ECA, uma das medidas aplicáveis aos pais - e a mais gravosa delas - é a suspensão ou destituição do poder familiar (BRASIL, 1990). Cumpre informar, portanto, quais seriam as faltas que poderiam ensejar a aplicação dessa medida tão rigorosa.

O Código Civil, em seu artigo 1.635, disciplina quais são as formas de extinção do poder 
familiar: (1) pela morte dos pais ou do filho; (2) pela emancipação; (3) pela maioridade; (4) pela adoção e (5) por decisão judicial, na forma do artigo 1.638. Por óbvio, as situações previstas nos incisos I (morte dos pais ou do filho) e III (maioridade), do artigo 1.635, são irreversíveis e, portanto, nestas hipóteses, não há que se falar em possibilidade de restituição do poder familiar. Quanto à emancipação e à adoção, estas também são pacíficas na doutrina e na jurisprudência, uma vez que são medidas irrevogáveis. Assim sendo, também não há possibilidade de restituição do poder familiar na hipótese em que o infante foi emancipado ou já tiver sido adotado por outra família. No que se refere à adoção, esclarece a irrevogabilidade o parágrafo $1^{\circ}$, do artigo 39 , da Lei $\mathrm{n}^{\circ} 8.069 / 90$ (ECA), in verbis:

Art. 39. A adoção de criança e de adolescente reger-se-á segundo o disposto nesta Lei.

$\S 1^{\circ} \mathrm{A}$ adoção é medida excepcional e irrevogável, à qual se deve recorrer apenas quando esgotados os recursos de manutenção da criança ou adolescente na família natural ou extensa, na forma do parágrafo único do art. 25 desta Lei (BRASIL, 1990).

O presente estudo, por não ter o escopo de discorrer de forma mais aprofundada quanto às hipóteses de extinção do poder familiar irreversíveis (morte dos pais ou do filho, emancipação, maioridade ou adoção), limita-se a apresentar a única forma em que há perspectiva de restituição da autoridade parental, qual seja a modalidade prevista pelo inciso V, do artigo 1.635, do Código Civil - por decisão judicial, na forma do artigo 1.638, que traz:

Art. 1.638. Perderá por ato judicial o poder familiar o pai ou a mãe que:

I - castigar imoderadamente o filho;

II - deixar o filho em abandono;

III - praticar atos contrários à moral e aos bons costumes;

IV - incidir, reiteradamente, nas faltas previstas no artigo antecedente (BRASIL, 2002).

Quanto ao inciso IV, do artigo 1.638, cumpre colacionar o teor do artigo antecedente (1.637):

Art. 1.637. Se o pai, ou a mãe, abusar de sua autoridade, faltando aos deveres a eles inerentes ou arruinando os bens dos filhos, cabe ao juiz, requerendo algum parente, ou o Ministério Público, adotar a medida que lhe pareça reclamada pela segurança do menor e seus haveres, até suspendendo o poder familiar, quando convenha.

Parágrafo único. Suspende-se igualmente o exercício do poder familiar ao pai ou à mãe condenados por sentença irrecorrível, em virtude de crime cuja pena exceda a dois anos de prisão. (BRASIL, 2002).

Quanto à modalidade de suspensão prevista no parágrafo único do artigo 1.637, cabe 
mencionar a ressalva do parágrafo $2^{\circ}$, do artigo 23, do ECA, que elucida que a condenação criminal do pai ou da mãe não implicará a destituição do poder familiar, exceto na hipótese de condenação por crime doloso, sujeito à pena de reclusão, contra o próprio filho ou filha. Isso significa que, em caso de condenação criminal de um dos genitores por sentença irrecorrível cuja pena exceda a dois anos de prisão, haverá mera suspensão do poder familiar. No entanto, esta condenação pode ensejar a efetiva destituição da autoridade parental, no caso de a conduta criminosa ter sido praticada dolosamente contra o próprio filho ou filha.

O ECA ainda traz mais uma causa que pode ensejar a perda e a suspensão do poder familiar, conforme o artigo 24, qual seja o descumprimento injustificado dos deveres e obrigações a que alude o art. 22 do mesmo diploma legal:

Art. 22. Aos pais incumbe o dever de sustento, guarda e educação dos filhos menores, cabendo-lhes ainda, no interesse destes, a obrigação de cumprir e fazer cumprir as determinações judicias.

Parágrafo único. A mãe e o pai, ou os responsáveis, têm direitos iguais e dever e responsabilidades compartilhados no cuidado e na educação da criança, devendo ser resguardado o direito de transmissão familiar de suas crenças e culturas, assegurados os direitos da criança, estabelecidos nesta Lei (BRASIL, 1990).

Destaca-se ainda que a mera falta ou carência de recursos materiais não constitui motivo suficiente para perda ou a suspensão do poder familiar. Tal previsão legal traz vedação expressa à criminalização da pobreza, uma vez que a existência de parcos recursos econômicos por parte do núcleo familiar, não pode ser a única e exclusiva causa para sanção tão gravosa, desde que a família cumpra adequadamente com os deveres inerentes ao exercício do poder familiar.

Um dos questionamentos que merece destaque acerca do tema da suspensão e/ou destituição do poder paternal é: "para onde vão as crianças e adolescentes os quais o Poder Judiciário decidiu que não mais devem ficar sob os cuidados dos genitores?" Em regra, com fulcro no princípio da preservação da família, estes devem ser encaminhados para os cuidados de membros da família extensa. No entanto, nem sempre há parentes dispostos a recepcioná-los, ou, em alguns casos, é possível perceber um contexto familiar tão fragilizado que não há possibilidade de recebê-los. Ainda, existem situações em que a urgência da retirada da criança ou adolescente do seio da família, a fim de protegê-los, é tão grande, que não há tempo hábil para verificar a existência de familiares extensos de imediato. Nestas hipóteses, os infantes são encaminhados para instituições de acolhimento.

Conforme apresentado por Nascimento (2012), com a vigência do já revogado Código de Menores, imperava a lógica de que seria preferível a institucionalização de crianças e adolescentes à permanência em suas famílias pobres. Estabeleceu-se associação entre recursos financeiros escassos e incapacidade moral para criar e educar os filhos, surgindo discursos, crenças e práticas que passaram a justificar a internação dos filhos de família pobre. A autora, no entanto, argumenta que a mera positivação do artigo 23 do ECA, que vedou essa medida, não se estabelece, por si só, 
enquanto prática. No cenário atual, a família pobre foi ganhando nova categorização, qual seja, a de família negligente, o que passou a justificar a intervenção estatal e a continuidade da retirada de crianças e adolescentes de suas famílias.

No mesmo sentido, Teixeira e Vieira (2015) defendem que até 1988 crianças e adolescentes eram indistintamente denominados de menores e eram tratados como objetos de proteção dos pais e do Estado. Neste viés, o Código de Menores surge de um histórico tratamento excludente, cujas práticas existem desde o Brasil-Colônia e que, apesar de terem sido modificadas com o tempo, não alteraram a sua essência, qual seja, a institucionalização e o consequente rompimento de vínculos familiares e sociais.

No estudo elaborado por Durán-Strauch, Guáqueta-Rodríguez e Torres-Quintero (2011), os autores concluíram que, assim como no Brasil, no que se relaciona aos direitos de proteção a crianças e adolescentes da Colômbia, há uma clara preocupação do país pelo conhecimento e pela descrição de diferentes situações de vulnerabilidades de seus direitos, bem como pela análise de suas causas e consequências. Contudo, os estudos locais pecam no tocante às ações dirigidas ao restabelecimento dos direitos vulnerados. Foram encontrados diversos problemas, como a conduta predominante de institucionalização assumida pelos juízes locais, os quais privavam de liberdade crianças e adolescentes, fundamentando-se em razões como a pobreza da família, o consumo de substâncias psicoativas, a violência intrafamiliar e riscos de exploração ou abuso.

Souza e Britto (2015) apresentam que, de acordo com o documento que reúne orientações técnicas para acolhimento, elaborado pelo Conselho Nacional dos Direitos da Criança e do Adolescente (CONANDA) e pelo Conselho Nacional de Assistência Social (CNAS), essa modalidade de atendimento consiste em:

Serviço que oferece acolhimento, cuidado e espaço de desenvolvimento para grupos de crianças e adolescentes em situação de abandono ou cujas famílias ou responsáveis encontram-se temporariamente impossibilitados de cumprir sua função de cuidados e proteção. Oferece atendimento especializado e condições institucionais para o acolhimento em padrões de dignidade, funcionando como moradia provisória até que seja viabilizado o retorno à família de origem ou, na sua impossibilidade, o encaminhamento para família substituta. (SOUZA; BRITTO, 2015, p. 43-44).

Nesse sentido, Guedes e Scarcelli (2014) definem a visão que se tem dos acolhimentos:

A função institucional do abrigo, como lugar de cuidado e proteção, estabelecida pelas legislações e almejada pelos atores institucionais, funda, ao mesmo tempo, aspectos que são depositados como representantes do fora. O abrigo era considerado por todos um lugar onde as crianças estariam protegidas. Já as violências, maus tratos e negligências eram temáticas esperadas - visto que eram essas ocorrências que legitimavam a existência da instituição - em parentes das crianças que estavam acolhidas, ou mesmo em outros equipamentos públicos, sempre no fora. Assim, delimitava-se tanto a função da instituição quanto as representações esperadas às crianças, aos familiares e aos agentes institucionais 
(GUEDES; SCARCELLI, 2014, p. 64-65).

Contudo, em que pese o ideal que se tem dos chamados "abrigos" como instituições que realmente conseguem proteger crianças e adolescentes acolhidos, nem sempre essa expectativa atende à realidade social. Analisando casos práticos de acolhimentos institucionais de crianças e adolescentes em Aracajú/SE, Souza e Britto (2015) constataram que as instituições de acolhimento do município ainda não cumprem com todas as diretrizes propostas pelo ECA, acarretando uma série de violações aos direitos das crianças e dos adolescentes lá inseridos. As autoras identificaram que alguns dos problemas constatados inerentes à execução do acolhimento são: desmembramento de grupo de irmãos, instituições que restringem o atendimento a crianças de determinadas faixa etária, desarticulação da rede de proteção à infância e à adolescência, significativo número de crianças e adolescentes do interior acolhidos na capital, ausência de trabalho com a família, além de dificuldades para efetivação do direito à convivência familiar e comunitária.

No mesmo sentido, Guedes e Scarcelli (2014), tendo como referência trabalho desenvolvido a partir de experiências práticas no Serviço de Acolhimento Institucional para Crianças e Adolescentes (SAICA), trazem o relato de descoberta de ocorrência de abuso sexual dentro de um abrigo, praticado por adolescente que residia desde pequeno no local. A visão maniqueísta de que as famílias de fora do acolhimento são as causadoras dos malefícios aos infantes e de que o abrigo é a instituição que os mantém a salvo, cai por terra. As autoras lançam então o seguinte questionamento:

Há um lugar a salvo de riscos? Nesse sentido, as dificuldades encontradas pela equipe diante dessa situação em grande parte se relacionam à necessidade que lidar com o ocorrido impõe colocar em questão a posição do abrigo e de cada um. Não por acaso era um assunto tão difícil e pouco falado. (GUEDES; SCARCELLI, 2014, p. 65).

Não se quer aqui menosprezar o papel fundamental que as instituições de acolhimento desempenham no cenário atual. Evidente que há situações graves em que não há outra opção, senão acolher a criança ou o adolescente vítima de violência, maus-tratos ou negligência. $\mathrm{O}$ que se pretende é romper com a visão de que, em quaisquer circunstâncias, a institucionalização seria a medida que melhor atenderia aos interesses de infantes e adolescentes.

Entende-se que existem casos em que a retirada da criança do núcleo familiar pode não ser a solução mais adequada. Dessa forma, a atuação do Estado deveria se dar de forma preventiva, objetivando evitar situações de violência intrafamiliar. Ainda assim, mesmo quando a ocorrência de maus-tratos já houver se verificado, ideal seria a intervenção estatal no sentido de reestruturação do núcleo familiar, a fim de evitar a reincidência dessas práticas.

Teixeira e Vieira (2015) esclarecem que a convivência dentro do núcleo familiar é caracterizada pela participação ativa de todos os membros do grupo, devendo as pessoas em desenvolvimento ser estimuladas a participar do dia a dia da família, bem como das decisões 
familiares, o que contribui na formação de sua autonomia. Os autores concluíram que a participação ativa nas rotinas e nos rituais familiares é fator que proporciona sentimento de pertencimento à família, favorecendo a autoestima e a satisfação familiar. A criança intuitivamente sabe que a definição de lugar e de sua individualidade se dá na família, sendo as referências de segurança lá fornecidas essenciais para a instrução desses sentimentos. Nesse diapasão, Bowlby (1982 apud TEIXEIRA; VIEIRA, 2015) explica que a criança tende a aprender a agir observando o comportamento daqueles que ela admira ou com os quais se identifica. Assim sendo, crianças e adolescentes alijados da convivência familiar crescem sem referências, sem ter pessoas em quem confiar e para orientá-los no processo de amadurecimento, prejudicando sobremaneira a formação de sua identidade.

Nesse sentido, a restituição do poder familiar pode surgir como uma das medidas específicas de proteção à criança e ao adolescente, uma vez que o rol do artigo 101 do ECA não é taxativo. Em alguns casos, pode ser verificado que o retorno do infante ao seio de sua família natural é a medida que mais bem atende ao seu interesse, em vez de mantê-lo em instituições de acolhimento. Cabe, portanto, ao Juízo, na análise do caso concreto, verificar se as condições que ensejaram a destituição do poder familiar não mais persistem e a criança ou adolescente não estaria inserido em situação de risco, conforme se passa a expor.

\section{DA RESTITUIÇÃO DO PODER FAMILIAR À LUZ DO ORDENAMENTO JURÍDICO BRASILEIRO}

A possibilidade de restituição do poder familiar está longe de ser unanimidade na doutrina e na jurisprudência pátria. Alguns autores defendem a tese de sua impossibilidade ${ }^{3}$ e, de fato, existem inúmeros argumentos que merecem ser considerados nessa linha de raciocínio. O ponto central desta discussão surge da omissão legislativa quanto à possibilidade ou não de se restituir a autoridade parental daqueles que o haviam perdido por decisão judicial. Silenciou o legislador quanto à solução do tema, no entanto, como bem se sabe, não é facultada ao magistrado a possibilidade de se eximir de decidir os casos que chegam ao seu conhecimento com base na mera inexistência de dispositivo legal específico.

$\mathrm{O}$ artigo $4^{\mathrm{o}}$, da Lei de Introdução às Normas do Direito Brasileiro (LINDB) esclarece que, quando a lei for omissa, o juiz decidirá o caso de acordo com a analogia, os costumes e os princípios gerais do direito (BRASIL, 1942). No âmbito dos direitos inerentes à infância e juventude, de acordo com o que foi abordado em tópico anterior, o Juízo deve ter por norte os princípios gerais da proteção integral e prioritária, do interesse superior da criança e do adolescente, bem como da prevalência da família.

Nessa senda, mister recorrer aos ensinamentos de Miguel Reale (2001) que elenca, entre outras, a jurisprudência como uma das fontes do direito:

3 (FONSECA, 2000; ZEGLIN, 2015). 
A jurisprudência, muitas vezes, inova em matéria jurídica, estabelecendo normas que não se contêm estritamente na lei, mas resultam de uma construção obtida graças à conexão de dispositivos, até então considerados separadamente, ou, ao contrário, mediante a separação de preceitos por largo tempo unidos entre si. Nessas oportunidades, o juiz compõe, para o caso concreto, uma norma que vem complementar o sistema objetivo do Direito (REALE, 2001, p. 159).

Isto posto, infere-se que, havendo omissão legal sobre determinado tema, cabe ao magistrado, utilizando-se da analogia, dos costumes e dos princípios gerais do direito, julgar o caso. Outrossim, ainda é possível constatar que a jurisprudência, entendida como "[...] uma série de julgados que guardem, entre si, uma linha essencial de continuidade e coerência" (REALE, 2001, p. 158), consubstancia-se como uma das fontes através das quais emana o direito. Complementa ainda o autor que "[...] o juiz constitui norma para o caso concreto toda vez que houver lacuna na lei, assim como nos casos em que lhe couber julgar por equidade" (2001, p. 159).

Quanto ao papel da doutrina, Reale esclarece que esta:

[...] banha as matrizes do Direito, indagando do papel histórico e da função atual de cada uma delas, das relações de dependência existentes entre as diversas fontes do direito em cada País e em cada ciclo histórico, e, indo além, esclarecenos sobre o significado das normas ou modelos que das fontes derivam. [...] A doutrina, por conseguinte, não é fonte do Direito, mas nem por isso deixa de ser uma das molas propulsoras, e a mais racional das forças diretoras, do ordenamento jurídico (REALE, 2001, p. 168-169).

Desta feita, esclarecendo o papel da jurisprudência e da doutrina, como fonte do direito e como força diretora do ordenamento jurídico, respectivamente, cabe apresentar o que trazem os estudos de doutrinadores, bem como os precedentes jurisprudenciais sobre o tema da restituição do poder familiar. Já fora abordado que o poder familiar compreende o exercício de inúmeros direitos e deveres inerentes a ele. Nesse sentido, existem diversas hipóteses legais de suspensão e até destituição dos genitores que incorram em faltas graves. Pasini e Trentin (2015) esclarecem que existem casos em que os pais conseguem superar os motivos ensejadores da destituição do poder paternal e buscam recuperar o convívio com sua prole.

Caio Mário da Silva Pereira (1987 apud COMEL, 2003) também advogava o caráter revogável da destituição do poder familiar, ao argumento de que a ideia predominante em matéria de assistência, proteção, salvaguarda e defesa de crianças e adolescente é o melhor interesse dos mesmos. Na mesma linha de raciocínio, Santos Neto (1994) apresenta que a maior parte das leis estrangeiras admite a recuperação do poder familiar, pressuposta tal conveniência, em caso de regeneração dos inibidos ou de desaparecimento das causas que determinaram a sanção. $\mathrm{O}$ autor ainda faz ressalva interessante ao dizer que a possibilidade de restituição do poder familiar não se fundamenta como um direito de os pais se recuperarem do possível impedimento de exercer a autoridade parental, mas surge como direito da criança ou do adolescente - que se viu afastado do convívio com o núcleo familiar -, de retomar os laços com seus genitores, com vistas aos princípios 
da proteção integral, do melhor interesse e da prevalência da família natural.

No mesmo sentido, Orlando Gomes (2000, p. 399, apud PASINI; TRENTIN, 2015, p. 71) elucida que "[...] o pátrio poder perdido pode ser restabelecido, provada a regeneração do pai ou desparecida a causa que determinou a reintegração do múnus, de que o pai foi privado, deve ser pleiteada judicialmente pelo interessado".

Noutro giro, Fonseca (2000) aduz que existem divergências entre os autores no que se refere à definitividade da extinção do poder familiar, por meio da destituição, e que, apesar de não ser este o seu posicionamento, reconhece que a maior parte da doutrina entende que, cessada a causa motivadora da destituição, a autoridade parental perdida poderá ser recuperada. Argumenta o autor que, no seu entender, a destituição do poder familiar é definitiva, mormente ao se considerar que não há garantias de que os genitores privados de seu mister não reiterarão nas condutas que os fizeram perder a autoridade parental em primeiro plano. Há, na visão do autor, possibilidade de retomada dos vínculos familiares apenas na hipótese em que houve mera suspensão do poder parental, mas não quando for levada a efeito a efetiva destituição.

Do mesmo modo, Zeglin (2015) sustenta que a perda do poder familiar, por meio de decisão judicial, é medida excepcional e, em tese, definitiva. A autora ressalva que a Constituição Federal assegura aos genitores o direito ao contraditório e à ampla defesa, só sendo decretada judicialmente a perda do vínculo parental quando observado o devido processo legal e somente nas situações expressamente previstas em lei. Assim, ante a gravidade desta sanção, não se admite interpretação extensiva para a sua aplicação, a qual somente deverá ocorrer se atender ao superior interesse da criança ou do adolescente.

Por outra via, é possível constatar ainda que, pautando-se em interpretação sistemática das disposições contidas no ECA, evidencia-se que a única medida "irreversível”, por ser expressamente irrevogável, é a adoção, conforme apresenta o art. $39, \S 1^{\circ}$, do ECA. Diante do silêncio da lei acerca do restabelecimento do poder familiar, também se poderia inferir, a contrario sensu, pela possibilidade de reversão da destituição da autoridade parental ${ }^{4}$. No mesmo sentido, Vieira Júnior e Melotto (2011) explicitam que o ECA em nenhum de seus dispositivos qualifica a medida de destituição do poder familiar como definitiva, sendo a irrevogabilidade inerente apenas à adoção.

No direito comparado, verifica-se que, nas legislações internacionais, a tendência tem sido admitir a recondução do genitor afastado das funções, cessadas as causas que motivaram o afastamento, colocando sempre o interesse da criança em primeiro lugar (COMEL, 2003). No estudo realizado por Akel (2009, apud PASINI; TRENTIN, 2015, p. 69), apresenta-se que:

No direito comparado, a maioria das legislações admite o restabelecimento do poder familiar, desde que cessadas as causas que ensejaram a destituição e a recondução favorável ao menor. Entre os quais, cita-se o Código Civil espanhol (art. 170-1, CCE), a legislação civil de Portugal (art. 1.916, CC) e o direito civil argentino (art. 308, CC).

4 Precedente: TJ-RS - AC: 70058335076 (RIO GRANDE DO SUL, 2014). 
Nessa senda, transcreve-se o conteúdo do artigo 308 do "Código Civil de la República Argentina":

“Art. 308. - Lá privación de la autoridade de los padres podrá ser dejada sin efecto por el juez si los padres demonstraran que, por circunstancias nuevas, la restituicion se justifica em beneficio o interés de los hijos". (ARGENTINA, 1869).

No direito português, há norma determinando que seja levantada a inibição do poder paternal decretada pelo tribunal quando cessem as causas que lhe deram origem, o que pode ser feito a todo tempo, desde que passado um ano da sentença de inibição ou da que houver desatendido pedido anterior de levantamento (COMEL, 2003) .

Por sua vez, com base nos estudos de Durán-Strauch, Guáqueta-Rodríguez e TorresQuintero (2011), verifica-se que a Colômbia, em 2006, promulgou novo "Código de Infancia y Adolescencia" que se adequou aos compromissos internacionais. Tal diploma legal, assim como o ECA, pauta-se pelos seguintes princípios: (I) Interés superior del niño, (II) Protección integral e (III) Prevalencia de derechos, dentre outras diretrizes.

Como se vê, portanto, no direito estrangeiro há compromisso manifesto e claro com o princípio da proteção integral do infante. Via de regra, a privação da autoridade paternal pode ser superada, desde que cessados os motivos que a ensejaram, quaisquer que sejam eles, havendo interesse do filho que assim recomende (COMEL, 2003). A autora conclui:

[...] mesmo se reconhecendo o caráter de definitividade da perda do poder familiar, não há que se tê-lo de modo absoluto, admitindo-se a recondução do pai faltoso ao encargo se o interesse e bem-estar do filho reclamarem, o que, de resto, implicará, dentre outros, prova bastante de que restou superada a situação que ensejou a medida (COMEL, 2003, p. 298).

Feitas estas considerações, cabe verificar como os tribunais brasileiros têm decidido acerca da questão da possibilidade de reversão da destituição do poder familiar, tendo-se em vista que a jurisprudência também pode ser considerada como fonte normativa. Cumpre, portanto, colacionar a ementa do seguinte julgado, proveniente do Tribunal de Justiça do Rio Grande do Sul (TJ-RS):

APELAÇÃO CÍVEL. ECA.AÇÃO DERESTITUIÇÃO DO PODER FAMILIAR. POSSIBILIDADE JURÍDICA DO PEDIDO. PROTEÇÃO INTEGRAL E PRIORITÁRIA DOS DIREITOS DA CRIANÇA E DO ADOLESCENTE. DESCONSTITUIÇÃO DA SENTENÇA EXTINTIVA.

1. A atenta e sistemática leitura dos artigos do Estatuto da Criança e do Adolescente permite concluir que apenas a adoção tem caráter irrevogável, porque expressamente consignado no $\S 1^{\circ}$ do art. 39. Diante do silêncio da lei acerca do restabelecimento do poder familiar, também se pode concluir, a

\footnotetext{
5 Código Civil Português, art. 1.916: 1. A inibição do exercício das responsabilidades parentais decretada pelo tribunal será levantada quando cessem as causas que lhe deram origem. 2. O levantamento pode ser pedido pelo Ministério Público, a todo o tempo, ou por qualquer dos pais, passado um ano sobre o trânsito em julgado da sentença de inibição ou da que houver desatendido outro pedido de levantamento" (PORTUGAL, 1967).
} 
contrário senso, pela possibilidade da reversão da destituição do poder familiar, desde que seja proposta ação própria para tanto, devendo restar comprovada a modificação da situação fática que ensejou o decreto de perda do poder familiar. Desse modo, impõe-se a desconstituição da sentença que extinguiu o processo por impossibilidade jurídica do pedido.

2. À luz da doutrina da proteção integral e prioritária dos direitos da criança e do adolescente preconizada pelo ECA, a intervenção do Estado deve atender prioritariamente aos superiores interesses dos menores, nos termos do art. 100, inc. II e IV, do ECA, de modo que, caso o retorno dos menores ao convívio materno se mostre a medida que melhor atenda aos seus interesses, não há motivos para que se obste tal retorno, com a restituição do poder familiar pela genitora, mormente porque os menores não foram encaminhados à adoção.

3. Trata-se, no caso, de uma relação jurídica continuativa, sujeita, portanto, à ação do tempo sobre seus integrantes (tal qual ocorre com as relações jurídicas que envolvem o direito a alimentos). Logo, a coisa julgada, formal e material, que antes se tenha produzido, fica preservada desde que as condições objetivas permaneçam as mesmas (cláusula rebus sic stantibus). No entanto, modificadas estas, outra poderá ser a decisão, sem que haja ofensa à coisa julgada. DERAM PROVIMENTO. UNÂNIME. (Apelação Cível nº 70058335076, Oitava Câmara Cível, Tribunal de Justiça do RS, Relator: Luiz Felipe Brasil Santos, Julgado em 22/05/2014, Data de publicação: Diário da Justiça: 27/05/2015). (RIO GRANDE DO SUL, 2014).

A possibilidade do restabelecimento do poder familiar é, inclusive, uma das teses jurídicas institucionais da Defensoria Pública do Estado de São Paulo e que, portanto, norteia sua atuação. No IV Encontro Estadual de Defensores Públicos de São Paulo, ocorrido em 04 de dezembro de 2010 , a tese $01 / 10$ foi aprovada com o seguinte teor.

Diante do princípio da primazia da família natural, é possível a reconstituição do poder familiar, por meio de ação própria, desde que os pais passem a viabilizar melhores condições aos filhos, mesmo após o trânsito em julgado ou após o prazo para ação rescisória da decisão que os destituíram do poder familiar, salvo se já consolidado o regular processo de adoção a terceiros. (ESCOLA DA DEFENSORIA PÚBLICA DO ESTADO DE SÃO PAULO, 2010).

Dessa forma, não há que se falar que a restituição do poder familiar perdido por decisão judicial transitada em julgado ofenda a coisa julgada formal e/ou material, uma vez tratar-se de relação jurídica continuativa e que se sujeita, por conseguinte, à ação do tempo sobre seus integrantes, da mesma maneira que ocorre com as relações jurídicas que envolvam o direito a alimentos. Sendo assim, a coisa julgada anteriormente produzida fica preservada, desde que as condições objetivas permaneçam as mesmas. No entanto, modificadas estas, outra poderá ser a decisão ${ }^{6}$.

\section{CONCLUSÃO}

6 Precedente: TJ-RS - AC: 70058335076 RS. (RIO GRANDE DO SUL, 2014). 
A destituição do poder familiar, em não raras oportunidades, fundamenta-se inegavelmente em questões socioeconômicas, muito embora isso seja vedado expressamente pelo ordenamento jurídico brasileiro (Art. 23, ECA). Diferentes variáveis socioemocionais podem influir nessa tomada de decisões e, portanto, trata-se de situação complexa e de diferente manejo.

Nesse sentido, torna-se primordial a compreensão sistêmica das causas que podem levar a destituição do poder familiar, a fim de se analisar e mais bem avaliar as possibilidades de recolocação de crianças e adolescentes em famílias destituídas. Pela amplitude e complexidade do fenômeno, as opiniões e pareceres sobre a restituição não são unânimes, o que possibilita que novas reflexões e propostas possam ser cogitadas.

Defende-se, ante todas as considerações apresentadas ao longo deste trabalho, a possibilidade de restituição do poder familiar, na hipótese em que os genitores o haviam perdido por decisão judicial, ainda que transitada em julgado. No entanto, para tal, por tratar-se de relação jurídica de trato continuado, faz-se necessário que os pais faltosos comprovem, por meio de ação autônoma, que, de fato, superaram as condições que os fizeram perder o poder paternal.

Assim sendo, evidente que temática tão complexa e delicada demanda escorreita dilação probatória, bem como o acompanhamento psicológico dos genitores e do infante ou adolescente durante o curso do processo, para que os pareceres psicológicos - e médicos, quando necessário - comprovem a inexistência das causas que ensejaram a destituição. Processos de avaliação psicológica destinados às pessoas envolvidas podem contribuir sobremaneira na melhor decisão para as situações que se apresentam. Esses processos caracterizam-se por práticas de avaliação realizadas mediante a aplicação de instrumentos psicológicos cientificamente comprovados e que permitem ao profissional de psicologia levantar informações a respeito dos indivíduos e da dinâmica familiar, favorecendo assim tomadas de decisões mais precisas e justas por parte dos magistrados.

Evidente que a destituição da autoridade parental, por ser a mais drástica das sanções, pressupõe a existência de falta gravíssima por parte dos genitores. Assim sendo, a possibilidade de reversão desta medida requer extrema cautela por parte dos sujeitos do processo, consubstanciandose como verdadeira exceção. Dessa forma, compete ao Juízo da Infância e Juventude analisar as condições do caso concreto, a fim de atender ao princípio do melhor interesse da criança ou do adolescente alvo da medida de proteção. Sugere-se que, existindo ação de restabelecimento do poder familiar e comprovada a superação dos fatos ensejadores da destituição, o magistrado promova o contato progressivo entre pais e filhos, fixando, em um primeiro momento, mero direito de visitas.

Há que se destacar que a restituição do poder familiar só poderá ocorrer levando-se em consideração os princípios da proteção integral e prioritária, do superior interesse e da preservação da família. Assim, em que pese estes postulados, em sua gênese, regerem apenas a aplicação das medidas de proteção, evidencia-se que todas as disposições contidas no ECA devem ser interpretadas tendo-os como base. Nesse diapasão, verificando-se que o retorno do infante ao 
seio de sua família natural (princípio da preservação da família), é medida que mais bem atende aos seus interesses (princípio do interesse superior) e se mostra eficaz a atender suas necessidades (princípio da proteção integral e prioritária), seria incoerente sua vedação.

Ademais, embora a possibilidade de restabelecimento da autoridade parental não seja unanimidade nos estudos de doutrinadores ou nos julgados dos tribunais brasileiros, verifica-se que, à luz do direito comparado, a recondução dos pais faltosos ao encargo de cuidar de seus filhos é prevista em uma série de diplomas normativos estrangeiros.

No direito estrangeiro pesquisado há compromisso manifesto e claro com os princípios da proteção integral do infante e da preservação da família. Via de regra, a privação da autoridade parental pode ser superada, desde que cessados os motivos que a ensejaram, quaisquer que sejam eles, havendo interesse do filho que assim recomende.

Além disso, há precedentes dentro do nosso ordenamento jurídico que indicam a possibilidade jurídica deste tipo de ação, definindo que, à luz da doutrina da proteção integral e prioritária, caso o retorno dos menores ao convívio materno se mostre a medida que melhor atenda aos seus interesses, não há razão para sua obstrução.

Ad argumentandum tantum, através de raciocínio analógico é possível constatar que, pautando-se em interpretação sistemática das disposições contidas no ECA, evidencia-se que a única medida "irreversível”, por ser expressamente irrevogável, é a adoção, conforme apresenta o art. 39, $\S 1^{\circ}$, do ECA. Diante do silêncio da lei acerca do restabelecimento da autoridade parental, também se poderia inferir, a contrario sensu, pela possibilidade de reversão da medida de destituição do poder.

Cumpre esclarecer que mesmo a definitividade da adoção já foi flexibilizada em recente precedente do STJ, estabelecendo-se que o princípio do interesse superior tem a possibilidade de retirar a peremptoriedade de qualquer texto legal atinente aos interesses de crianças ou do adolescente, submetendo-o a um crivo objetivo de apreciação judicial.

Destarte, se o único instituto caracterizado pelo ECA como irreversível pode ser moldado por força do princípio geral do melhor interesse, parece coerente afirmar que a destituição da autoridade parental, que não é definida como imutável em nenhum de seus dispositivos, pode ser revogável, desde que esta medida seja compatível com a base principiológica inerente aos direitos da criança e do adolescente.

Ressalta-se também que o Juízo da Infância e da Juventude deve atender sempre aos fins sociais propostos pelo Estatuto da Criança e do Adolescente e, por esta razão, muitos de seus dispositivos podem ser moldados em virtude dos princípios que norteiam este diploma legal, tendo-se sempre em mira a proteção da criança ou do adolescente.

Nada impede, além disso, que a restituição do poder familiar surja como umas das próprias medidas protetivas à criança ou ao adolescente, porquanto o rol previsto no artigo 101 do ECA não é taxativo, mas meramente exemplificativo. Esta conclusão decorre de seu próprio caput, que apresenta que "verificada qualquer das hipóteses previstas no art. 98, a autoridade competente poderá determinar, dentre outras, as seguintes medidas [...]” (BRASIL, 1990). 
Nesse sentido, o artigo 98 do ECA admite o cabimento das medidas de proteção sempre que os direitos reconhecidos neste diploma normativo forem ameaçados ou violados, seja por ação ou omissão da sociedade ou do Estado; seja por falta, omissão ou abuso dos pais ou responsáveis em razão da própria conduta da criança ou adolescente alvo da medida protetiva (BRASIL, 1990).

Poder-se-ia dizer, nestes termos, que sendo violado o direito à convivência familiar e comunitária por ação do Estado, na medida em que este determinou o afastamento da criança ou do adolescente de seu núcleo familiar, seria cabível a utilização da restituição do poder familiar como uma medida protetiva.

No entanto, a recolocação da criança ou adolescente em família destituída do poder familiar não pode se pautar apenas por critérios técnicos e jurídicos, sem levar em conta a realidade social em que o núcleo familiar está inserido. Tampouco pode considerar os aspectos psicológicos e sociais, sem fundamentar-se nos critérios de legalidade, vez que se está sob a égide de um Estado Democrático de Direito. Nesse sentido, tema tão delicado e complexo jamais pode ser observado sob a ótica de apenas uma área do conhecimento. Consideramos que ações transdisciplinares poderão favorecer tomadas de decisão mais consistentes para cada caso específico.

A pesquisa bibliográfica realizada para produzir este artigo revelou que existem poucos estudos relacionados ao seu tema principal, ou seja, a possibilidade de restituição do poder familiar mediante a superação das situações que ensejaram sua perda. Configura-se, assim, lacuna de conhecimentos que necessita ser mais bem explorada, visando dar ao assunto maior visibilidade e contribuindo, assim, para a reestruturação das famílias vulneráveis.

Por todo o exposto, evidencia-se que a restituição do poder familiar se configura como temática bastante complexa e que demanda, por parte do Estado e daqueles que atuam no meio jurídico, olhar cuidadoso, visando sempre à tomada das medidas mais eficientes e adequadas ao caso concreto.

\section{REFERÊNCIAS}

ARGENTINA. Código Civil de la República Argentina. Buenos Aires, 1869. Disponível em: https://www.oas.org/dil/esp/Codigo_Civil_de_la_Republica_Argentina.pdf. Acesso em: $10 \mathrm{fev}$. 2017.

BARROS, Guilherme Freire de Melo. Direito da criança e do adolescente. 3. ed. Salvador: JusPODIVM, 2015.

BRASIL. [Constituição (1988)]. Constituição da República Federativa do Brasil. Brasília, DF: Senado Federal: Centro Gráfico, 1988.

BRASIL. Decreto-Lei n ${ }^{\circ}$ 4.657, de 04 de setembro de 1942. Dispõe sobre a Lei de Introdução às Normas do Direito Brasileiro. Diário Oficial da União: seção 1, Brasília, DF, p. 13635, 09 set. 1942.

BRASIL. Lei ${ }^{\circ}$ 8.069, de 13 de julho de 1990. Dispõe sobre o Estatuto da Criança e do Adolescente e dá outras providências. Diário Oficial da União: seção 1, Brasília, DF, p. 13563, 
16 jul. 1990.

BRASIL. Lei n ${ }^{\circ} 10.406$ de 10 de janeiro de 2002. Institui o Código Civil. Diário Oficial da União: seção 1, Brasília, DF, p. 1, 11 jan. 2002.

BRASIL. Lei no 6.697, de 10 de outubro de 1979. Institui o Código de Menores. Diário Oficial da União: seção 1, Brasília, DF, p. 14945, 11 out. 1979.

BRASIL. Superior Tribunal de Justiça. Estatuto da criança e do adolescente: guarda e adoção. Brasília: STJ, 2014. (STJ - Jurisprudência em Teses, n. 27, de 04.02.2014). Disponível em: www. stj.jus.br/.../jurisprudencia/jurisprudenciaemteses/Jurisprudência $\% 20 \mathrm{em} \% 20 \mathrm{Teses} \%$. Acesso em: 10 fev. 2017.

COMEL, Denise Damo. Do poder familiar. São Paulo: Revista dos Tribunais, 2003.

DURÁN-STRAUCH, Ernesto; GUÁQUETA-RODRÍGUEZ, Camilo Andrés; TORRES-

QUINTERO, Astrid. Restablecimiento de derechos de niños, ninãs y adolescentes em el sistema nacional de bienestar familiar. Revista Latinoamericana de Ciencias Sociales, Niñez y Juventud, Manizales, v. 2, n. 9, p. 549-559, 2011.

\section{ESCOLA DA DEFENSORIA PÚBLICA DO ESTADO DE SÃO PAULO. Infância e}

Juventude. São Paulo, 9 nov. 2010. Tese 01/10. Disponível em: https://www.defensoria.sp.def. br/dpesp/Default.aspx?idPagina=5194. Acesso em: 10 fev. 2017.

FONSECA, Antônio Cezar Lima da. A ação de destituição do pátrio poder. Revista de Informação Legislativa, Brasília, v. 37, n. 146, p. 261-279, abr. 2000.

GUEDES, Carina Ferreira; SCARCELLI, Ianni Regia. Acolhimento institucional na assistência à infância: o cotidiano em questão. Psicologia \& Sociedade, Belo Horizonte, MG., v. 26, n. esp., p. 58-67, abr. 2014.

LÔBO, Paulo Luiz Netto. Do poder familiar. In: DIAS, Maria Berenice; PEREIRA, Rodrigo da Cunha (coord.). Direito de família e o novo código civil. Belo Horizonte: Del Rey, 2005.

NASCIMENTO, Maria Lívia do. Abrigo, pobreza e negligência: percursos da judicialização. Psicologia \& Sociedade, Belo Horizonte, MG., v. 24, n. esp., p. 39-44, 2012.

PASINI, Vivian Carla Lamberti; TRENTIN, Fernanda. Restabelecimento do poder familiar: reintegração à família natural. Interfaces Científicas, Aracajú, v. 1, n. 1, p. 64-74, out. 2015.

PORTUGAL. Código civil português. Lisboa: PGD, 1967. Disponível em: http://www.pgdlisboa.pt/leis/lei_mostra_articulado.php?artigo_ id=775A1916\&nid=775\&tabela=leis\&pagina $=1 \&$ ficha $=1 \&$ so_miolo $=\& n v e r s a o=\#$ artigo. Acesso em: 10 fev. 2017.

REALE, Miguel. Lições preliminares de Direito. 25. ed. São Paulo: Saraiva, 2001.

RIO GRANDE DO SUL. Tribunal de Justiça ( $8^{a}$ Câmara Cível). Apelação Cível n 70058335076. ECA. ação de restituição do poder familiar. Possibilidade jurídica do pedido. proteção integral e prioritária dos direitos da criança e do adolescente. Desconstituição da sentença extintiva. Relator: Des. Luiz Felipe Brasil Santos, 22 de maio de 2014. Disponível em: https://www.jusbrasil.com.br/diarios/DJSP/2014/05/27. Acesso em: 27 maio 2014. 
SANTOS NETO, José Antônio de Paula. Do pátrio poder. São Paulo: Editora Revista dos Tribunais, 1994.

SOUZA, Fernanda Hermínia Oliveira; BRITTO, Leila Maria Torraca de. Acolhimento institucional de crianças e adolescentes em Aracajú. Psicologia Clínica, Rio de Janeiro, v. 27, n. 1, p. 41-57, 2015.

TEIXEIRA, Ana Carolina Brochado; VIEIRA, Marcelo de Mello. Construindo o direito à convivência familiares de crianças e adolescentes no Brasil: um diálogo entre as normas constitucionais e a Lei n. 8/069/1990. Civilistica.com, Rio de Janeiro, ano 4, n. 2, 2015. Disponível em: http://civilistica.com/construindo-o-direito-a-convivencia-familiar. Acesso em: 6 mar. 2017.

VIEIRA JÚNIOR, Ênio Gentil; MELOTTO, Amanda Oliari. Os pais destituídos do poder familiar e a obrigação de prestar alimentos. Revista da Esmesc, Florianópolis, v. 18, n. 24, 2011.

ZEGLIN, Helena Vonsovicz. A destituição do poder familiar e a adoção: efeitos patrimoniais na atualidade e a possibilidade de multiparentalidade. 2015. $81 \mathrm{f}$. Trabalho de Conclusão de Curso (Graduação em Direito) - Centro de Ciências Jurídicas, Universidade Federal de Santa Catarina, Florianópolis, 2015.

Como citar: GOULART JUNIOR, Edward Goulart; GOULART, João Pedro Minguete. Restituição do poder familiar: considerações acerca de sua possibilidade jurídica. Revista do Direito Público, Londrina, v. 14, n. 1, p. 83-102, abr. 2019. DOI: 10.5433/1980-511X2019v14n1p83. ISSN: 1980$511 X$.

Recebido em: 14/02/2017.

Aprovado em: 22/11/2018. 